\title{
Equivalent missense variant in the FOXP2 and FOXP1 transcription factors causes distinct neurodevelopmental disorders
}

\author{
Elliot Sollis $^{1}$ (D) | Pelagia Deriziotis ${ }^{1}$ (D) | Hirotomo Saitsu² ${ }^{\text {(D) }}$ | Noriko Miyake $^{3}$ (D) | \\ Naomichi Matsumoto $^{3}$ (D) | Mariëtte J.V.Hoffer ${ }^{4}$ (D) | Claudia A.L. Ruivenkamp ${ }^{4}$ (D) \\ Mariëlle Alders $^{5}$ iD | Nobuhiko Okamoto ${ }^{6}$ iD | Emilia K. Bijlsma ${ }^{4}$ | Astrid S. Plomp ${ }^{5}$ | \\ Simon E. Fisher ${ }^{1,7}$ (iD)
}

${ }^{1}$ Language and Genetics Department, Max Planck Institute for Psycholinguistics, Nijmegen, The Netherlands

${ }^{2}$ Department of Biochemistry, Hamamatsu University School of Medicine, Hamamatsu, Japan

${ }^{3}$ Department of Human Genetics, Yokohama City University Graduate School of Medicine, Yokohama, Japan

${ }^{4}$ Department of Clinical Genetics, Leiden University Medical Center, Leiden, The Netherlands

${ }^{5}$ Department of Clinical Genetics, Academic Medical Center, Amsterdam, The Netherlands

${ }^{6}$ Department of Medical Genetics, Osaka Medical Center and Research Institute for Maternal and Child Health, Osaka, Japan

${ }^{7}$ Donders Institute for Brain, Cognition and Behaviour, Nijmegen, The Netherlands

Correspondence

Simon E. Fisher, Language and Genetics Department, Max Planck Institute for Psycholinguistics, Nijmegen 6525XD, The Netherlands.

Email:simon.fisher@mpi.nl

Contract grant sponsors: Max-PlanckGesellschaft; Japan Agency for Medical Research and Development ('Practical Research Project for Rare/Intractable Diseases').

Communicated by María-Jesús Sobrido

\begin{abstract}
The closely related paralogues FOXP2 and FOXP1 encode transcription factors with shared functions in the development of many tissues, including the brain. However, while mutations in FOXP2 lead to a speech/language disorder characterized by childhood apraxia of speech (CAS), the clinical profile of FOXP1 variants includes a broader neurodevelopmental phenotype with global developmental delay, intellectual disability, and speech/language impairment. Using clinical whole-exome sequencing, we report an identical de novo missense FOXP1 variant identified in three unrelated patients. The variant, p.R514H, is located in the forkhead-box DNA-binding domain and is equivalent to the well-studied p.R553H FOXP2 variant that cosegregates with CAS in a large UK family. We present here for the first time a direct comparison of the molecular and clinical consequences of the same mutation affecting the equivalent residue in FOXP1 and FOXP2. Detailed functional characterization of the two variants in cell model systems revealed very similar molecular consequences, including aberrant subcellular localization, disruption of transcription factor activity, and deleterious effects on protein interactions. Nonetheless, clinical manifestations were broader and more severe in the three cases carrying the p.R514H FOXP1 variant than in individuals with the p.R553H variant related to CAS, highlighting divergent roles of FOXP2 and FOXP1 in neurodevelopment.
\end{abstract}

KEYWORDS

FOXP1, FOXP2, functional characterization, neurodevelopmental disorder

\section{1 | INTRODUCTION}

The FOXP2 (MIM\# 605317; NM_014491.3; NP_055306.1) and FOXP1 (MIM\# 605515; NM_032682.5; NP_116071.2) genes are very closely related paralogues with important roles in embryonic development, including in the brain (Bacon et al., 2015; French \& Fisher, 2014; Shu et al., 2007; Wang et al., 2004). They encode transcription factors of the forkhead-box (FOX) family and display a high degree of similarity at the amino acid level (total protein: 64\% identity, 82\% similarity; FOX DNAbinding domain: $87 \%$ identity, $96 \%$ similarity). FOXP2 and FOXP1 can heterodimerize via a leucine zipper domain to regulate transcription
(Li, Weidenfeld, \& Morrisey, 2004), and in brain regions where they are coexpressed, such as the striatum and certain cortical neurons in layers 5 and 6 (Ferland, Cherry, Preware, Morrisey, \& Walsh, 2003; Hisaoka, Nakamura, Senba, \& Morikawa, 2010), they may cooperatively regulate downstream targets (O'Roak et al., 2011; Vernes et al., 2008).

Heterozygous disruptions of FOXP2 and FOXP1 cause distinct neurodevelopmental phenotypes (Lai, Fisher, Hurst, Vargha-Khadem, \& Monaco, 2001; Sollis et al., 2016). FOXP2 variants cause a rare form of neurodevelopmental disorder characterized by severe speech deficits (childhood apraxia of speech [CAS]) accompanied by impairments in expressive and receptive language affecting oral and written domains 
(MIM\# 602081) (Lai et al., 2001). In contrast, mutations in FOXP1 cause a broader neurodevelopmental syndrome involving global developmental delay, intellectual disability (ID), speech/language impairment, and autistic features (MIM\# 613670) (Sollis et al., 2016). These phenotypic differences are consistently evident despite a similar spectrum of causative variants in the two genes, which includes nonsense, frameshift, and missense variants (Supp. Table S1, Deciphering Developmental Disorders Study, 2016; Hamdan et al., 2010; Lozano, Vino, Lozano, Fisher \& Deriziotis, 2015; Roll et al., 2010; Srivastava et al., 2014; Turner et al., 2013), as well as larger deletions (Carr et al., 2010; Feuk et al., 2006), and therefore seems to provide evidence of distinct roles for FOXP2 and FOXP1 in neurodevelopment. However, it is also possible that this disparity could instead be explained by the different amino acid changes so far documented in each gene (Supp. Table S1). Thus far, there are no published studies comparing directly equivalent pathogenic variants in FOXP2 and FOXP1.

The most rigorously studied etiological FOXP2 variant is an arginine-to-histidine substitution at residue 553 (p.R553H) cosegregating with CAS in multiple members of a large multigenerational UK pedigree (Lai et al., 2001). Note that other studies, such as Reuter et al. (2016), have used a different isoform (NM_148898.3; NP_683696.2) for FOXP2 annotation, and therefore refer to the $\mathrm{p} . \mathrm{R} 553 \mathrm{H}$ variant as p.R578H. The affected arginine residue in FOXP2 lies within the FOX DNA-binding domain and makes direct contact with the backbone of the target DNA to which the protein binds when acting as a transcription factor (Stroud et al., 2006). Human cell-based assays have shown that the p.R553H variant alters subcellular localization and abolishes transcriptional repression activity (Vernes et al., 2006). Moreover, electrophoretic mobility shift assays have robustly demonstrated that the p.R553H variant prevents the FOX domain from binding to DNA (Vernes et al., 2006). The functional importance of R553 is further highlighted in in vivo studies of mice that are heterozygous for an equivalent p.R552H variant and display impaired motor skill learning, decreased synaptic plasticity, and altered firing properties in corticostriatal circuits, as well as producing sequences of ultrasonic vocalizations with reduced complexity (Chabout et al., 2016; French et al., 2012; Groszer et al., 2008).

In the present study, we report for the first time an arginine-tohistidine substitution at the equivalent residue of FOXP1 (p.R514H), the result of an identical heterozygous de novo variant in three unrelated probands. This provides a unique opportunity to directly compare equivalent mutations in FOXP2 and FOXP1. We present thorough functional characterization of the p.R514H FOXP1 variant in human cellular models, assessing multiple protein characteristics and directly comparing the effects to those of the equivalent p.R553H FOXP2 variant. We also compare the clinical profile of the three p.R514H FOXP1 patients to the p.R553H FOXP2 phenotype.

\section{MATERIALS AND METHODS}

\section{1 | Whole-exome sequencing}

For Patient 1, whole-exome sequencing (WES) was performed as previously described (Fukai et al., 2015). In brief, approximately $3 \mu \mathrm{g}$ DNA was sheared and used for a SureSelect Human All Exon V5 library (Agilent Technologies, Santa Clara, CA) according to the manufacturer's instructions. Samples were sequenced on a HiSeq2000 (Illumina, San Diego, CA) with 101-bp paired-end reads. Of all variants within exons or \pm 30 bp from exon-intron boundaries, those registered in dbSNP137 (minor allele frequency >0.01), the National Heart Lung and Blood Institute Exome Sequencing Project Exome Variant Server (NHLBI-ESP 6500, https://evs.gs.washington.edu/EVS/), and an in-house database (exome data from 575 Japanese individuals) were removed. Variants were confirmed by Sanger sequencing using an $A B I$ PRISM 3500xl autosequencer (Life Technologies, Carlsbad, CA).

For Patient 2, exome sequencing was performed by GenomeScan (Leiden, The Netherlands), where exomes were enriched with the SureSelect Human All Exon V5 kit (Agilent Technologies) followed by Hiseq2500 system sequencing. The in-house sequence analysis pipeline MAGPIE (Modular GATK-Based Variant Calling Pipeline) based on read alignment using Burrows-Wheeler Alignment (BWA) (Li \& Durbin, 2009) and variant calling using Genome Analysis Toolkit (GATK) (McKenna et al., 2010) was used for quality control, and to generate BAM and VCF files. Variants were annotated using Variant Effect Predictor (VEP, Ensembl). Before variant analysis and interpretation was started, intergenic and frequent variants ( $>5 \%$ present in Genome of the Netherlands or the 1000 Genomes Project database) were excluded. Further filtering and analysis was performed using a custom-made version of the Leiden Open Variation Database (LOVD) called LOVDplus. The variant was confirmed by Sanger sequencing.

For Patient 3, WES was performed in a trio diagnostic approach (patient and both parents). Libraries were prepared using the Kapa HTP kit (Illumina) and capture was performed using the SeqCap EZ Exome v3.0 (Roche Nimblegen, Madison, WI). Sequencing was done on an Illumina HiSeq2500 HTv4 (Illumina) with paired-end 125-bp reads. Read alignment to hg19 and variant calling were done with a pipeline based on BWA-MEM0.7 and GATK 3.3. Variant annotation and prioritizing were done using Cartagenia NGS Bench (Cartagenia Inc., Cambridge, MA). Only one de novo variant was found in a gene panel for ID (consisting of 842 genes). The variant was confirmed by Sanger sequencing.

For all patients, informed consent was obtained for the use of the data and photographs according to relevant institutional and national guidelines and regulations.

\section{2 | Cell culture and transfection}

HEK293 cells (ATCC ${ }^{\circledR}$ CRL-1573 ${ }^{\text {TM }}$ ) were cultured in DMEM supplemented with $10 \%$ fetal bovine serum (both Invitrogen, Carlsbad, CA). Transfections were performed using GeneJuice, according to manufacturer's instructions (Merck-Millipore, Billerica, MA).

\section{3 | DNA constructs}

Wild-type (WT) FOXP1/2, TBR1 (MIM\# 604616) and CTBP1/2 (MIM\# 602618; 602619) were amplified by PCR and subcloned into pLuc, pYFP, and a modified pmCherry-C1 expression vector 
(Clontech, Mountain View, CA) as previously described (Deriziotis, Graham, Estruch, \& Fisher, 2014a; Deriziotis et al., 2014b; Estruch, Graham, Chinnappa, Deriziotis, \& Fisher, 2016a). Variants were generated using the QuikChange II Site-Directed Mutagenesis Kit (Agilent Technologies) using the following primers: FOXP1 p.R514H, sense 5'-ACGTGGAAGAATGCAGTGCATCA TAATCTTAGTCTTCAC-3' and antisense $5^{\prime}$-GTGAAGACTAAGATTA TGATGCACTGCATTCTTCCACGT-3'; FOXP2 p.R553H, sense 5'CTTGGAAGAATGCAGTACATCATAATCTTAGCCTGCAC- ${ }^{\prime}{ }^{\prime}$ and antisense 5' -GTGCAGGCTAAGATTATGATGTACTGCATTCTTCCAAG $3^{\prime}$. All constructs were verified by Sanger sequencing. FOXP DNA variants are numbered according to the CDNA reference sequences NM_032682.5 (FOXP1) and NM_014491.3 (FOXP2), where +1 is the A of the ATG translation initiation codon. The initiation codon is codon 1.

\section{4 | Western blotting}

Cells were transfected with equimolar concentrations of WT or variant FOXP1 expression plasmids and cultured for $24 \mathrm{hr}$. Whole-cell lysates were extracted by treatment with lysis buffer (100 mM Tris pH 7.5, $150 \mathrm{mM} \mathrm{NaCl}, 10 \mathrm{mM}$ EDTA, 0.2\% Triton X-100, 1\% PMSF, protease inhibitor cocktail; all from Sigma-Aldrich, St Louis, MO) for $10 \mathrm{~min}$ at $4^{\circ} \mathrm{C}$, before centrifuging at $10,000 \mathrm{~g}$ for $30 \mathrm{~min}$ at $4^{\circ} \mathrm{C}$ to remove cell debris. Proteins were resolved on a 4\%-15\% Tris-Glycine gel and transferred onto a polyvinylidene fluoride membrane (both Bio-Rad, Laboratories, Hercules, CA). Blots were probed with mouse anti-EGFP (for pYFP constructs; 1:8,000; Clontech) and mouse anti- $\beta$-actin (as loading control; 1:10,000; Sigma-Aldrich) overnight at $4^{\circ} \mathrm{C}$, followed by incubation with HRP-conjugated goat anti-mouse IgG for 60 min at room temperature (1:2,000; Bio-Rad). Proteins were visualized using Novex ECL Chemiluminescent Substrate Reagent Kit (Invitrogen) and the ChemiDoc XRS+ System (Bio-Rad).

\section{5 | Fluorescence microscopy}

Cells were seeded onto coverslips coated with poly-L-lysine (Sigma-Aldrich) and were fixed $24 \mathrm{hr}$ post-transfection using 4\% paraformaldehyde (Electron Microscopy Sciences, Hatfield, PA) for $10 \mathrm{~min}$ at room temperature. YFP and mCherry fusion proteins were visualized by direct fluorescence. HisV5-tagged proteins were visualized by immunofluorescence, using anti-V 5 primary antibody (SV5-Pk1; Gene Tex, Irvine, CA; 1:500) and donkey anti-mouse Alexa 488 secondary antibody (Invitrogen). Nuclei were visualized with Hoechst 33342 (Invitrogen). Fluorescence images were obtained using a Zeiss Axio Imager M2 upright microscope (Carl Zeiss AG, Oberkochen, Germany).

\subsection{Luciferase reporter assay}

Cells were seeded in 24-well plates and transfected with $45 \mathrm{ng}$ of firefly luciferase reporter construct (pGL3-prom; Promega, Madison, WI), $5 \mathrm{ng}$ of Renilla luciferase normalization control (pRL-TK; Promega) and 200 ng FOXP1 expression construct (WT or variant in pYFP) or empty vector (pYFP; control). Cells were lysed in 24-well plates with $1 \times$ Passive Lysis Buffer (Promega) $48 \mathrm{hr}$ post-transfection, and transferred to opaque white 96-well plates for luminescence measurements. Firefly luciferase and Renilla luciferase activities were measured in a TECAN F200PRO microplate reader with injectors using the Dual-Luciferase Reporter Assay system (Promega). Briefly, luminescence due to firefly and then Renilla luciferase activity was measured for $10 \mathrm{sec}$ after addition of Luciferase Assay Reagent II and Stop \& Glo Reagent, respectively. Each transfection was performed in triplicate and the experiment was conducted three times. The statistical significance of the luciferase reporter assays was analyzed using a one-way analysis of variance and a Tukey's post-hoc test.

\subsection{Bioluminescence resonance energy transfer assay}

Bioluminescence resonance energy transfer (BRET) assays were performed as previously described (Deriziotis et al., 2014a; Deriziotis et al., 2014b). In summary, cells were transfected with pairs of Renilla luciferase and YFP-fusion proteins in 96-well plates. Renilla luciferase and YFP fused to a C-terminal nuclear localization signal were used as control proteins. EnduRen luciferase substrate (Promega) was added to cells $48 \mathrm{hr}$ after transfection at a final concentration of $60 \mu \mathrm{M}$ and incubated for $4 \mathrm{~h}$. Emission measurements were taken with a TECAN F200PRO microplate reader using the Blue1 and Green1 filters and corrected BRET ratios were calculated as follows: [Green $1_{\text {(experimental condition) }} /$ Blue $1_{\text {(experimental condition) }}$ - Green $1_{\text {(control condition) }} /$ Blue $_{\text {(control condition) }}$ ]. YFP fluorescence was then measured separately, with excitation at $485 \mathrm{~nm}$ and emission at $535 \mathrm{~nm}$, to quantify expression of the YFP-fusion proteins. The statistical significance of the BRET assays was analyzed using independent two-sample t-tests.

\section{3 | RESULTS}

\subsection{Clinical description of patients}

Patient 1, a 2-year-old girl, is the third child of healthy and nonconsanguineous Japanese parents with no family history of neurological disease (Fig. 1A; Table 1). She was born at 36 weeks gestation. Her birth weight was 2,380 g, length was $47.5 \mathrm{~cm}$, and head circumference was $33 \mathrm{~cm}$. She was hypotonic and her developmental milestones were delayed. At 19 months of age, she could crawl and stand with support. Her physical growth was also disturbed. At 21 months of age, she had a height of $76.2 \mathrm{~cm}(-2.1 \mathrm{SD})$, weight of $7.6 \mathrm{~kg}(-2.7$ $\mathrm{SD})$, and head circumference of $45.0 \mathrm{~cm}(-1.1 \mathrm{SD})$. At 2 years, her language perception was poor and she did not speak any meaningful words. She exhibited signs of severe ID. During her infantile period, she experienced febrile seizures on three occasions. She also exhibited visual problems, including esotropia and hypermetropia. Biochemical examinations (blood cell count and blood smear, renal and liver function, uric acid, albumin, serum electrolytes, lactate, pyruvate, ammonia, amino acids, blood gases, thyroid function, and serum transferrin analysis) were normal. Genetic tests with normal results included karyotyping and array CGH. Electroencephalography and brain magnetic resonance imaging (MRI) showed no significant abnormalities. 
A

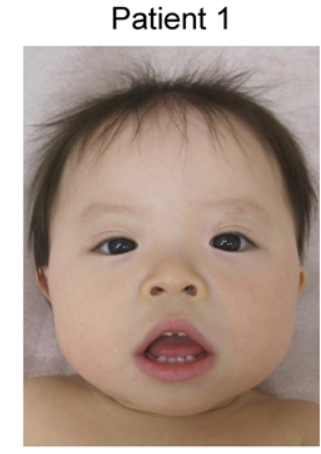

B
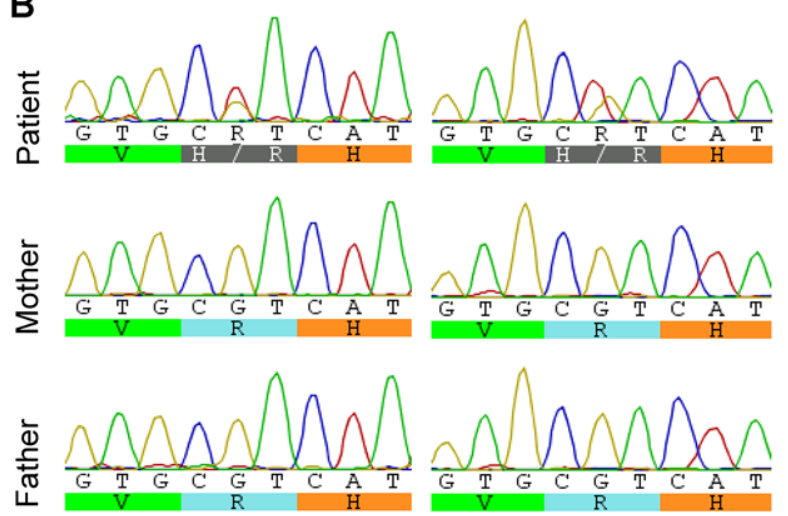

Patient 3
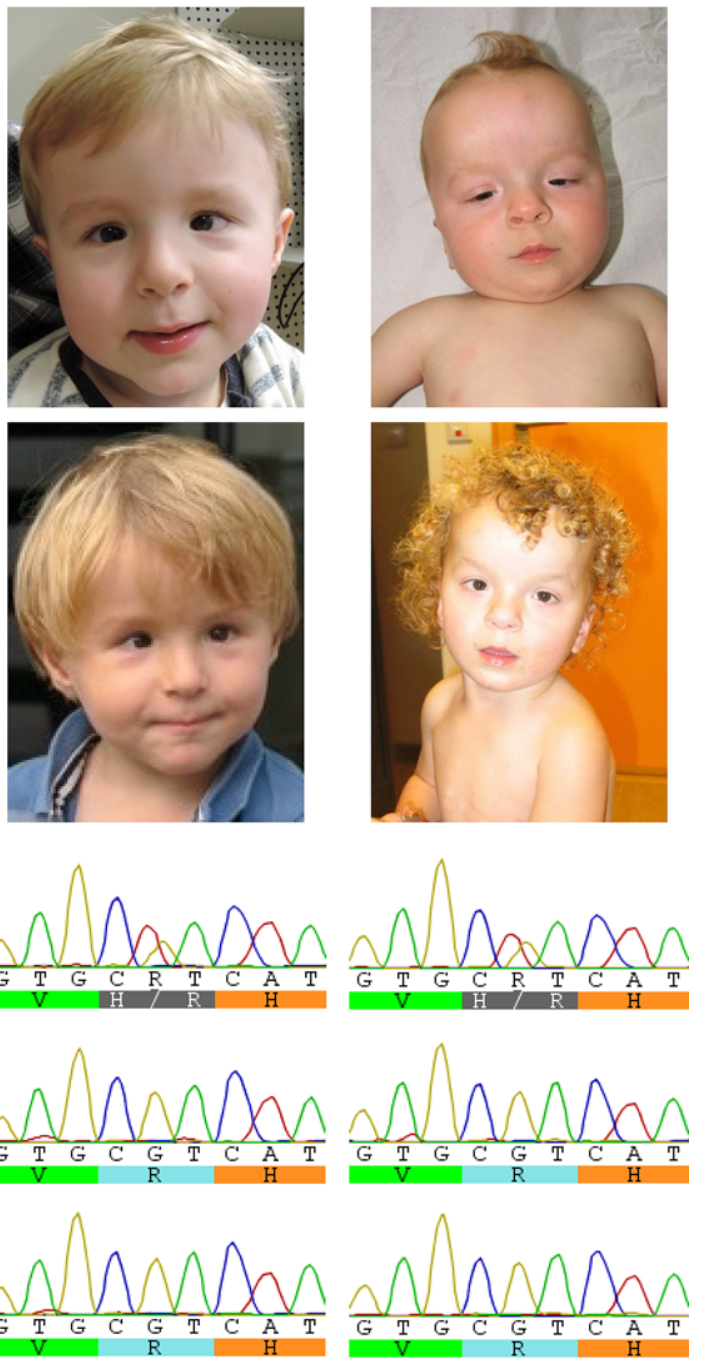

C
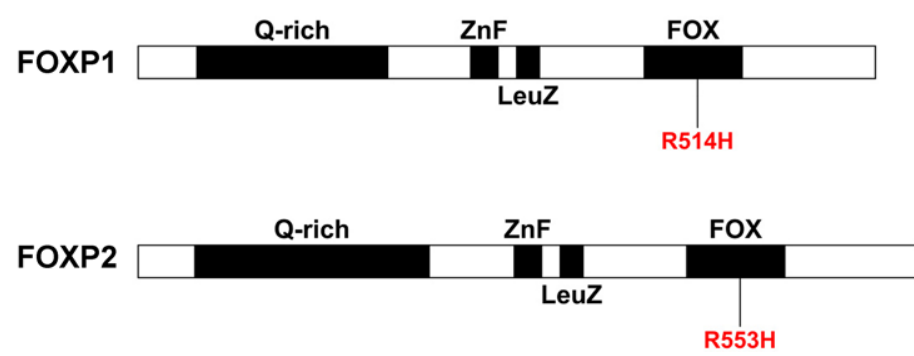

FIGURE 1 Identification of an identical de novo FOXP1 variant in three unrelated patients with global developmental delay. A: Photographs of Patients 1 (14 months), 2 (top: 2 year 6 months; bottom, 3 year 2 months), and 3 (top: 11.5 months; bottom: 3 year). B: Sanger traces of genomic DNA from the probands and their unaffected parents. C: Schematic representation of recombinant FOXP1 and FOXP2 proteins used in our assays. Both proteins contain a glutamine-rich region (Q-rich), and zinc finger (ZnF), leucine zipper (LeuZ), and FOX DNA-binding domains. The p.R514H FOXP1 and p.R553H FOXP2 variants at equivalent positions within the FOX domain are also labeled. The following cDNA and protein reference sequences were used for annotation in this article: FOXP1 transcript NM_032682.5 and protein NP_116071.2; FOXP2 transcript NM_014491.3 and protein NP_055306.1

Patient 2 is a 3-year-old Dutch boy born to healthy nonconsanguineous parents (Fig. 1A; Table 1). The father has a healthy daughter from a previous relationship. The mother has three male cousins (in one sibship) with developmental delay early in childhood, with catch-up later on. Family history is otherwise normal. He was born at 36 weeks gestation. His Apgar scores were 5/7/10 after 1/5/10 min, respectively, with signs of fetal distress due to a nuchal cord wrapped multiple times around the neck. His birth weight was 2,500 g. Developmental delay was noted at the age of 12 months. He started to walk independently at 26 months. At the age of 2 years and 5 months, he did not have a 
TA B LE 1 Phenotypic comparison of patients with de novo variants at residue 514 of FOXP1

\begin{tabular}{|c|c|c|c|c|}
\hline & Patient 1 & Patient 2 & Patient 3 & $\begin{array}{l}\text { Sollis et al. (2016) } \\
\text { (Patient 2) }\end{array}$ \\
\hline Variant & p.R514H & p.R514H & p.R514H & p.R514C \\
\hline Age & 2 years & 3 years 8 months & 7 years 11 months & 7 years \\
\hline Sex & Female & Male & Male & Male \\
\hline \multicolumn{5}{|c|}{ Neurodevelopmental features } \\
\hline Intellectual disability & Moderate & Mild & Moderate to severe & Mild to moderate \\
\hline $\begin{array}{l}\text { Speech and language } \\
\text { delay }\end{array}$ & + & + & + & + \\
\hline $\begin{array}{l}\text { Production more } \\
\text { severely affected than } \\
\text { comprehension }\end{array}$ & + & + & + & ND \\
\hline Autistic features & - & - & ND & $+(\mathrm{PDD}-\mathrm{NOS})$ \\
\hline Behavioral problems & ND & $\begin{array}{l}\text { Repetitive behavior, but } \\
\text { no major behavioral } \\
\text { problems }\end{array}$ & $\begin{array}{l}\text { No major behavioral } \\
\text { problems, some hand } \\
\text { biting, head banging }\end{array}$ & $\begin{array}{l}\text { Obsessions/compulsions, } \\
\text { stereotypic behavior, } \\
\text { impulsive behavior, } \\
\text { ADHD }\end{array}$ \\
\hline MRI & Normal & ND & $\begin{array}{l}\text { Mild widening of } \\
\text { extracerebral space }\end{array}$ & ND \\
\hline \multicolumn{5}{|l|}{ Motor and sensory features } \\
\hline Gross motor delay & + & + & + & + \\
\hline Hypotonia & + & - & - & + \\
\hline Sensory symptoms & - & $\begin{array}{l}\text { Highly sensitive to } \\
\text { temperature and } \\
\text { certain textures }\end{array}$ & - & $\begin{array}{l}\text { Sensory integration } \\
\text { disorder }\end{array}$ \\
\hline Visual symptoms & $\begin{array}{l}\text { Esotropia, } \\
\text { hypermetropia }\end{array}$ & $\begin{array}{l}\text { Strabismus, cerebral } \\
\text { visual impairment }\end{array}$ & $\begin{array}{l}\text { Strabismus, amblyopia, } \\
\text { hypermetropia }\end{array}$ & Strabismus \\
\hline \multicolumn{5}{|l|}{ Physical features } \\
\hline Growth delay & + & - & + & ND \\
\hline Prominent forehead & + & - & + & ND \\
\hline Macrocephaly & - & - & + & - \\
\hline $\begin{array}{l}\text { Eye-related } \\
\text { dysmorphisms }\end{array}$ & $\begin{array}{l}\text { Down-slanted } \\
\text { eyes }\end{array}$ & $\begin{array}{l}\text { Hypertelorism, short } \\
\text { palpebral fissures }\end{array}$ & Telecanthus, epicanthus & $\begin{array}{r}\text { Hypertelorism, small } \\
\text { down-slanted eyes }\end{array}$ \\
\hline Short nose with broad tip & + & ND & + & + \\
\hline Prominent digit pads & - & ND & + & ND \\
\hline $\begin{array}{l}\text { Urogenital } \\
\text { malformations }\end{array}$ & - & Cryptorchidism & $\begin{array}{l}\text { Cryptorchidism, small } \\
\text { penis }\end{array}$ & ND \\
\hline Other physical features & - & Sacral dimple & $\begin{array}{l}\text { Ears low set and tilted } \\
\text { back, thin upper lip, } \\
\text { crooked little toes, } \\
\text { curly hair (not familial) }\end{array}$ & Mild retrognathism \\
\hline Other medical problems & $\begin{array}{l}\text { Febrile seizures as } \\
\text { an infant }\end{array}$ & Recurrent otitis media & $\begin{array}{l}\text { Postnatal } \\
\text { hyperbilirubinemia, } \\
\text { severe sleep problems }\end{array}$ & Enuresis \\
\hline
\end{tabular}

Note:

ND, no data; PDD-NOS, pervasive developmental disorder not otherwise specified; ADHD, attention deficit/hyperactivity disorder.

pincer grip. Growth parameters were within the normal range. His speech was severely delayed and he used less than 10 single words, although comprehension was reported as good. On follow-up, at the age of 3 years and 6 months, he had developed more speech and was able to speak in sentences with 2-3 words. A recent IQ test (WIPPSIII$\mathrm{NL}$ ) showed a total IQ score of 60 . He is described as a friendly boy, with a tendency to repetitive behavior, but without major behavioral problems. Parents noticed that he is highly sensitive to temperature and to certain textures. He was born with undescended testes for which he had orchidopexy, a small umbilical hernia, and a sacral dimple. Other findings include a broad forehead, hypertelorism, short palpebral fissures with mild down slant at a younger age, and recurrent otitis media for which he received grommets. He has received treatment for strabismus and has been diagnosed with cerebral visual impairment. SNParray showed two small CNVs that were inherited from the unaffected mother.

Patient 3 is an 8-year-old Dutch boy born to healthy nonconsanguineous parents (Fig. 1A; Table 1). Growth delay was detected 
by ultrasound at 19 weeks. He was born at 39 weeks gestation and had good Apgar scores. He spent $24 \mathrm{hr}$ in an incubator with a little extra oxygen. Transient hypoglycemia was also noted. His birth weight was 2,710 g. A large head circumference prompted brain echography, which revealed no abnormalities. At the age of 3 days, he received phototherapy for hyperbilirubinemia. He exhibited many uncontrolled movements and could walk unsupported just before his 3rd birthday. His speech is profoundly delayed, with no speech at 7 years and 11 months. A postnatal hearing test was normal. Contact was good during the neonatal period, but parents found him less alert and less interested in his surroundings than other babies. He has had severe sleeping problems (awakening at night followed by staying awake for a long time, sleeping in the daytime), which was managed with melatonin. He did not have severe behavioral problems, but moved all day and showed occasional hand biting and head banging. He was born with undescended testes, underdevelopment of the scrotum, and a small penis. He received orchidopexy for one testis; the other was not found. At 7 years 11 months, he had a height of $124.5 \mathrm{~cm}$ (-1.5 SD), weight of $26 \mathrm{~kg}$ (+1 SD), and head circumference of $57.7 \mathrm{~cm}$ (>+2.5 SD). Other findings include prominent forehead, widow's peak, curly hair (not familial), low and posteriorly-rotated ears, low nasal bridge, mildly anteverted nares, telecanthus, epicanthus, thin upper lip, wide internipple distance, and fetal pads on the fingers. He has strabismus, and has been diagnosed with amblyopia and hypermetropia. Cytogenetic investigation revealed a normal male karyotype. FISH with subtelomeric probes, fragile $X$ screening, and metabolic investigations all returned normal results. DNA analysis of Noonan syndrome (like) genes (PTPN11, SOS1, KRAS, RAF1, BRAF, MAP2K1, MAP2K2, HRAS), as well as PTEN, identified no mutations. Array $\mathrm{CGH}$ also showed no abnormalities. Brain MRI showed mild widening of the extracerebral space.

\subsection{De novo missense FOXP1 variant identified in all three cases by clinical WES}

Clinical WES was performed with DNA from three probands and their unaffected parents to identify putative pathogenic variants. Using this method, we identified an identical heterozygous de novo missense FOXP1 variant present in all three unrelated probands (Fig. 1B; Table 1). Patient 1 carried an additional compound heterozygous variant in PEX10 (MIM\# 602859). Variants in PEX10 cause peroxisome biogenesis disorder, characterized by hepatic and renal abnormalities and ID (MIM\# 614870). Normal kidney and liver function in Patient 1 rule out a contribution toward the observed phenotype. No additional de novo variants were identified in the other two patients. Based on the available data, it was not possible to determine for any patient whether the de novo mutation had arisen on the paternal or maternal copy of the gene. The variant (NM_032682.5: c.1541G >A) was validated as de novo by Sanger sequencing (Fig. 1B) and has been submitted to the NCBI ClinVar database (https://www.ncbi.nlm.nih.gov/clinvar, accession SCV000494541).

The FOXP1 variant detected here results in an arginine to histidine substitution (p.R514H) within the DNA-recognition helix of the FOX DNA-binding domain (Fig. 1C). The severity of the mutation was assessed using PolyPhen-2 (v2.2.2r398; Adzhubei et al.,
2010; https://genetics.bwh.harvard.edu/pph2) and found to be probably damaging, with a score of 0.999 (sensitivity 0.09 , specificity 0.99). Cellular assays have demonstrated that the equivalent change in FOXP2 (p.R553H) found in cases of CAS results in abnormal localization, loss of DNA binding and transcriptional repression activity (Vernes et al., 2006). To investigate whether the p.R514H variant in FOXP1 results in disruption of protein function and to enable comparisons to the p.R553H variant in FOXP2, we performed detailed functional characterization of the two variants in parallel.

\section{3 | The p.R514H FOXP1 variant disrupts multiple protein functions}

FOXP variants were expressed as fusions with YFP or mCherry in HEK293 cells and produced proteins at the expected molecular weights (Fig. 2B). Unlike WT FOXP1, which is diffusely expressed in the nucleus, the p.R514H variant showed a small increase in cytoplasmic expression, and formed nuclear or cytoplasmic aggregates in $30 \%$ of cells, consistent with loss of function (Fig. 2A). Aberrant localization of the variant protein is observed not only in YFP fusion proteins, but also in FOXP1 tagged with a smaller HisV5 epitope (Supp. Fig. S1). Similarly, an increase in cytoplasmic expression and aggregation was observed for the variant at the equivalent residue in FOXP2 (p.R553H) (Fig. 2A; Supp. Fig. S1), as reported previously (Vernes et al., 2006). The crystal structure of the FOX domain from FOXP2 shows that R553 makes direct contact with the DNA backbone (Stroud et al., 2006). Accordingly, functional assays in human cells have shown that the p.R553H FOXP2 variant does not bind DNA carrying a consensus target sequence and cannot repress transcription (Vernes et al., 2006). Although there is no available crystal structure of FOXP1 bound to DNA, the FOX domains in FOXP1 and FOXP2 are $87 \%$ identical (Supp. Fig. S2). Therefore, we hypothesized that R514 in FOXP1 may also be crucial for transcriptional regulation, and used luciferase reporter assays to test this. Indeed, in our reporter assays, the p.R514H FOXP1 variant completely abolished transcriptional repression activity (Fig. 2C). Overall, these data indicate that, like R553 in FOXP2, this R514 residue is crucial for FOXP1 function.

To regulate transcription, FOXP1 forms homodimers and heterodimers with itself and other FOXP proteins, including FOXP2 (Li et al., 2004). We have previously demonstrated that de novo missense FOXP1 variants located in the FOX domain may exert a dominantnegative effect by interacting with and mislocalizing WT FOXP proteins to nuclear and cytoplasmic aggregates (Sollis et al., 2016). Similarly, the p.R553H variant in FOXP2 has recently been shown to interact with and mislocalize WT FOXP1 and FOXP2 proteins to the cytoplasm (Estruch et al., 2016a). We used the BRET assay to monitor protein interactions in live cells, and found that the p.R514H FOXP1 variant can interact with WT FOXP1 and FOXP2 proteins (Fig. 3A, and $\mathrm{B})$. Moreover, consistent with prior observations for FOXP variants disrupting the FOX domain (Estruch et al., 2016a; Sollis et al., 2016), the p.R514H variant mislocalizes WT FOXP1 and FOXP2 proteins to nuclear and cytoplasmic aggregates (Fig. 3C and D). Overall, these findings suggest that the pathogenic mechanism in these three 
A

YFP
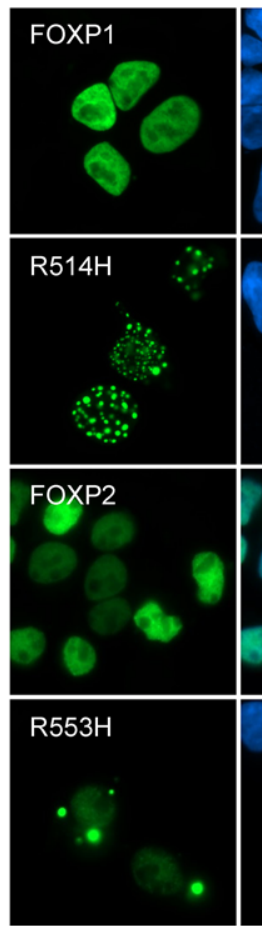

\begin{tabular}{|l|l|l|l|l|}
\hline & $\mathrm{N}$ & $\mathrm{N}+\mathrm{C}$ & $\mathrm{C}$ & Aggr. \\
\hline FOXP1 & $97 \%$ & $3 \%$ & $0 \%$ & $3 \%$ \\
\hline $\mathrm{R} 514 \mathrm{H}$ & $90 \%$ & $6 \%$ & $4 \%$ & $30 \%$ \\
\hline FOXP2 & $95 \%$ & $4 \%$ & $1 \%$ & $5 \%$ \\
\hline $\mathrm{R} 553 \mathrm{H}$ & $73 \%$ & $22 \%$ & $5 \%$ & $35 \%$ \\
\hline
\end{tabular}
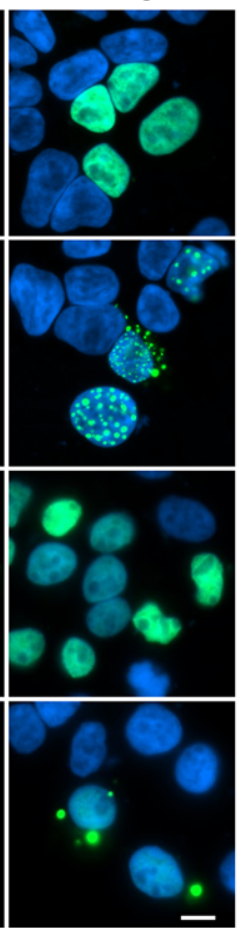

B

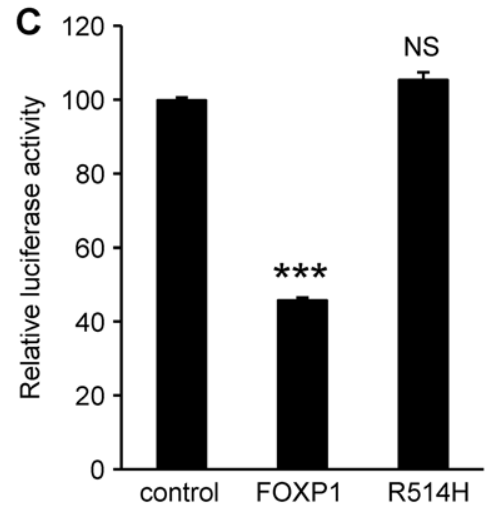

FIGURE 2 The p.R514H FOXP1 variant disrupts subcellular localization. A: Upper panel: Fluorescence microscopy images of HEK293 cells transfected with FOXP1/2 variants. FOXP proteins fused to YFP are shown in green. Nuclei were stained with Hoechst 33342 (blue). Scale bar $=10 \mu \mathrm{m}$. Lower panel: The percentage of cells expressing each FOXP protein variant in the nucleus only $(\mathrm{N})$, nucleus and cytoplasm ( $\mathrm{N}+\mathrm{C})$, or cytoplasm only (C). The percentage of cells containing protein aggregates (Aggr.) are also shown. More than 400 cells were scored for each variant. B: Immunoblotting of whole-cell lysates from HEK293 cells transfected with FOXP1 and FOXP2 variants fused to YFP. The control condition represents cells transfected with an empty pYFP plasmid. $\beta$-actin served as a loading control. C: Luciferase reporter assays for transcriptional regulatory activity of the p.R514H variant in HEK293 cells. Values are expressed relative to the control ( ${ }^{* *} P<0.001$; NS, not significant). The mean \pm SEM of three independent experiments performed in triplicate is shown

new patients may also involve a dominant-negative effect, conferred by the p.R514H FOXP1 variant.

Few interaction partners for FOXP proteins are currently known. Thus far, FOXP1 and FOXP2 have been shown to interact with the transcriptional corepressors CTBP1 and CTBP2 (Estruch et al., 2016a; Li et al., 2004) and the ASD-related TBR1 transcription factor (Deriziotis et al., 2014b). We assessed FOXP1 interactions with these partners, and found that the p.R514H variant retains the ability to interact with CTBP1 and CTBP2, and does not alter the localization of these two proteins in cotransfection experiments (Fig. 4). The same effect is seen with the p.R553H variant in FOXP2 (Fig. 4) (Estruch et al., 2016a). Interestingly, in our BRET assays, neither the p.R514H FOXP1 variant nor the p.R553H FOXP2 variant interacted with TBR1 (Fig. 5A) (Deriziotis et al., 2014b). Previous work has shown that the FOX domain is not required for FOXP2-TBR1 interaction (Deriziotis et al., 2014b), suggesting that damage to the FOX domain does not directly account for the loss of interaction observed here. Instead, the loss of interaction may result from aberrant localization of the FOXP variants. Indeed, although TBR1 partially colocalized with both FOXP variants when they occurred in the nucleus, TBR1 was absent from any nuclear or cytoplasmic aggregates formed by the variants (Fig. 5B).

\section{4 | DISCUSSION}

Our parallel functional characterization of the de novo $\mathrm{p} . \mathrm{R} 514 \mathrm{H}$ variant detected in three new patients and the pathogenic p.R553H FOXP2 variant previously found cosegregating with CAS has revealed similar effects on protein function. Both variants lead to aberrant subcellular localization and loss of transcriptional repression activity, and they exert the same effect on protein interactions with TBR1, CTBP1, and CTBP2. Notably, the two variants dimerize with WT FOXP1 and FOXP2 and translocate these proteins into nuclear and cytoplasmic aggregates. While the existence of FOXP whole-gene deletions 


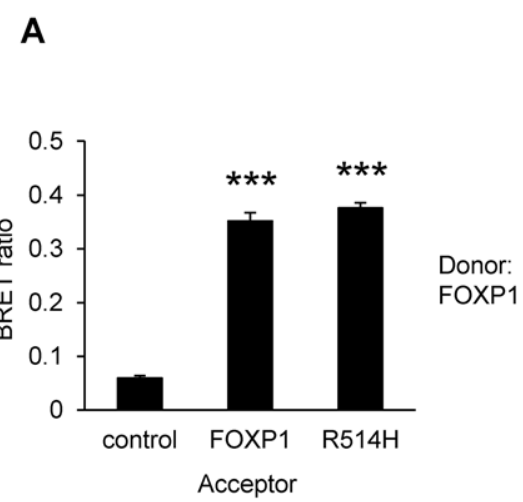

C
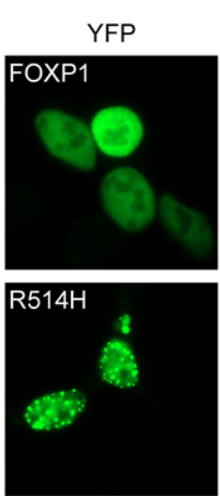

D
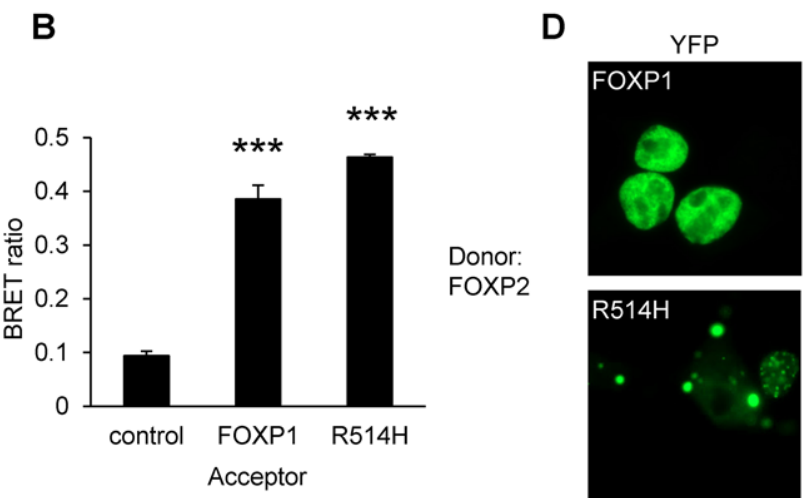

FOXP2

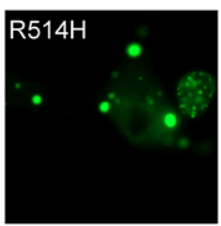

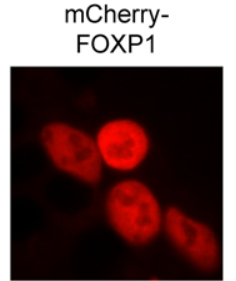
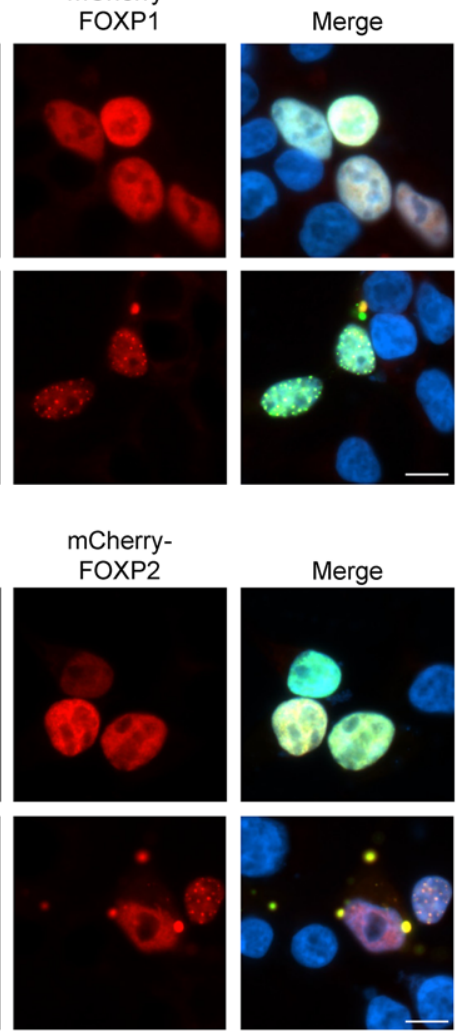

FIGURE 3 The p.R514H FOXP1 variant translocates WT FOXP proteins to nuclear and cytoplasmic aggregates. A and B: BRET assays for interaction between the p.R514H FOXP1 variant and WT FOXP1 or FOXP2. Bars represent the corrected mean BRET ratios \pm SD of one experiment performed in triplicate. Asterisks indicate significant differences compared with control ( ${ }^{* * *} P<0.001$, independent two-sample t-test). C: Fluorescence microscopy images of HEK293 cells cotransfected with WT FOXP1 (fused to mCherry, red) and either WT FOXP1 or p.R514H (fused to YFP, green). D: Fluorescence microscopy images of HEK293 cells cotransfected with WT FOXP2 (fused to mCherry, red) and either WT FOXP1 or p.R514H FOXP1 (fused to YFP, green). Nuclei were stained with Hoechst 33342 (blue). Scale bars $=10 \mu \mathrm{m}$

and truncating/frameshift variants points to haploinsufficiency as the key pathogenic mechanism, our findings here suggest an additional dominant-negative effect, whereby the FOXP1/2 variant prevents the WT protein from binding to DNA and regulating transcription.

Despite having very similar effects at the protein level, the matching arginine-to-histidine substitutions in FOXP1 and FOXP2 cause distinct neurodevelopmental phenotypes. The p.R514H FOXP1 variant results in broader and more severe effects on general cognition, motor development, and behavior, whereas the effects of the p.R553H FOXP2 variant are largely confined to speech, language processing, and orofacial motor function, with milder consequences for other aspects of cognition and development (Lai et al., 2001; Vargha-Khadem et al., 1998). These observations may be partly explained by the different expression patterns of FOXP1 and FOXP2 in the brain. Although both proteins are found in the striatum, the hippocampus expresses only FOXP1, and the Purkinje cells of the cerebellum express only FOXP2 (Ferland et al., 2003). In the cortex, expression is largely nonoverlapping, with FOXP1 detected in layers 3-5 and FOXP2 detected mainly in layer 6 and in restricted regions of layer 5 (Ferland et al., 2003; Hisaoka et al., 2010). In addition, FOXP1 and FOXP2 may be expressed in distinct neuronal subpopulations within the same brain regions, and even in cells where the two proteins are coexpressed, they may have distinct functions arising from differences in their downstream targets and/or interaction partners. In vitro studies suggest that certain genes important for nervous system development, including NEUROD1 and EFNB3, might be differentially regulated by different combinations of FOXP1/2/4 homodimers and heterodimers (Sin, Li, \& Crawford, 2015). Furthermore, an RNA sequencing study comparing downstream targets of Foxp1 and Foxp2 in mouse striatum found that only $12 \%$ of putative Foxp1 target genes were also targets of Foxp2 (Araujo et al., 2015). Differences between the two proteins have also been noted on assays of protein interaction; for example, the SUMO-protein ligase PIAS3 interacts with FOXP2 but not FOXP1 in live-cell assays (Estruch, Graham, Deriziotis, \& Fisher, 2016b). Future work comparing the interactome of FOXP1 and FOXP2 in appropriate models may further our understanding of the pathogenic mechanisms underlying the two distinct neurodevelopmental disorders.

In this study, we demonstrated that the p.R514H FOXP1 variant, like the p.R553H FOXP2 variant, prevents interaction with TBR1. This may have in vivo relevance in neuronal populations that coexpress FOXP1 and TBR1, including the hippocampus (Cipriani et al., 2016; Ferland et al., 2003) and a small subset of cortical neurons (Hisaoka et al., 2010). These regions differ from those that coexpress FOXP2 and TBR1, which include cortical layer 6 and amygdala (Ferland et al., 2003; Remedios et al., 2007). Other regions, such as the deep cerebellar nuclei, may express all three proteins (Ferland et al., 2003; Fink 

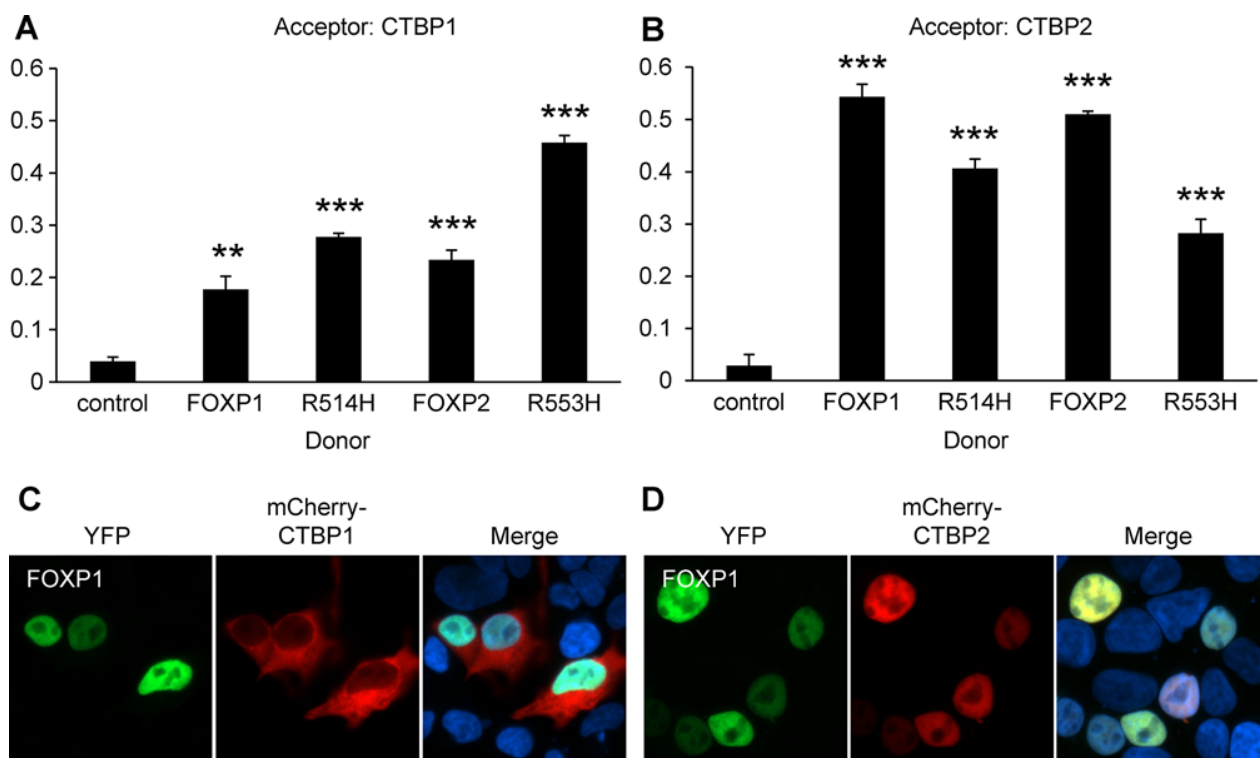

mCherry-

D CTBP1 YFP Merge
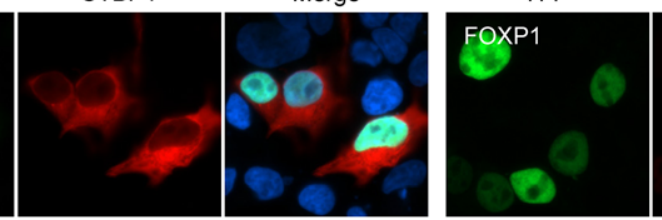

mCherry-
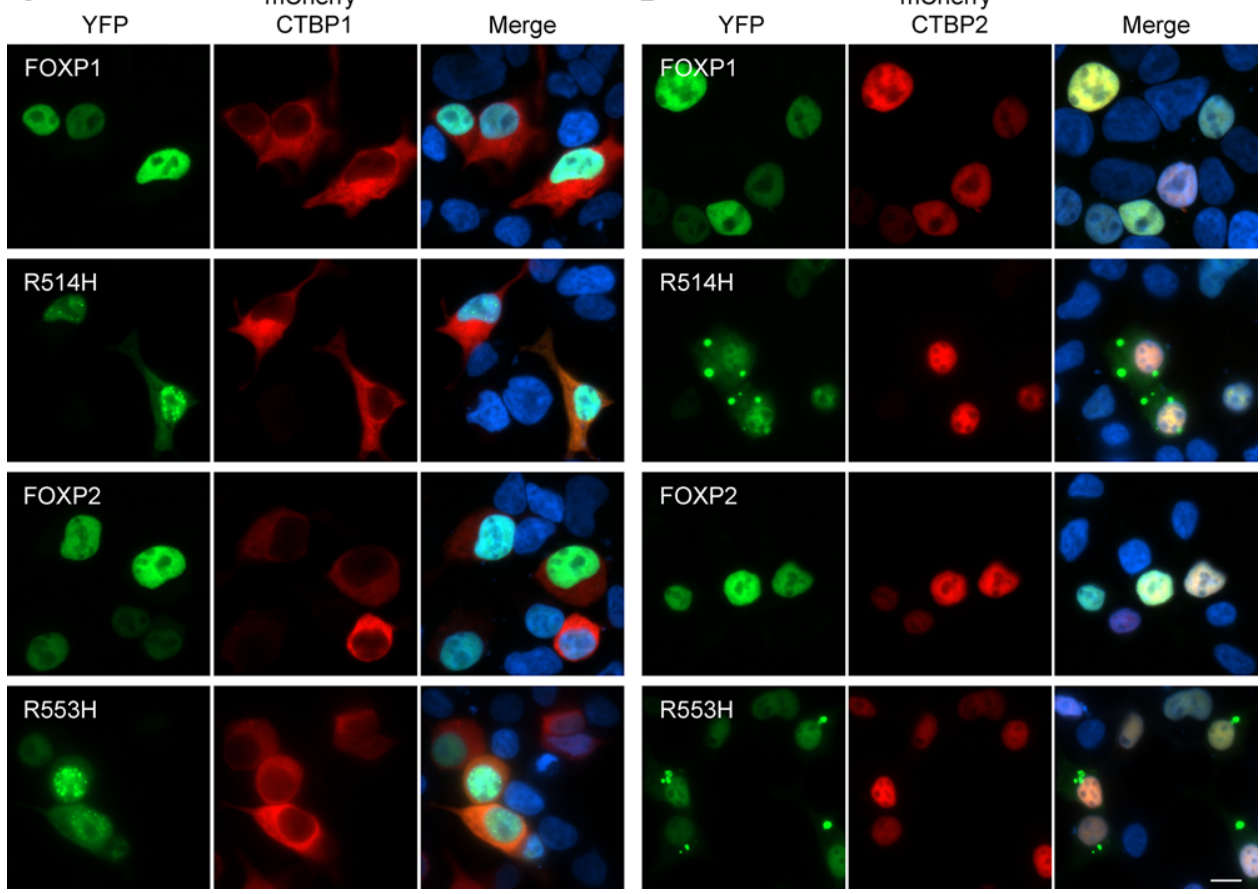

I GURE 4 The p.R514H FOXP1 variant maintains interactions with CTBP1/2. BRET assays for interaction between the $\mathrm{p}$. R514H FOXP1 variant and (A) CTBP1 or (B) CTBP2. The p.R553H FOXP2 variant is included for comparison. Bars represent the corrected mean BRET ratios \pm SD of one experiment performed in triplicate. Asterisks indicate significant differences compared with control $\left({ }^{* *} P<0.01\right.$, ${ }^{* * *} P<0.001$, independent twosample $t$-test). C: Fluorescence microscopy images of HEK293 cells cotransfected with CTBP1 (fused to mCherry, red) and FOXP1/2 variants (fused to YFP, green). D: Fluorescence microscopy images of HEK293 cells cotransfected with CTBP2 (fused to mCherry, red) and FOXP1/2 variants (fused to YFP, green). Nuclei were stained with Hoechst 33342 (blue). Scale bar $=10 \mu \mathrm{m}$

et al., 2006). Region-dependent consequences of impaired interaction with TBR1 in vivo may be another reason for the distinct phenotypic effects of the same mutation in FOXP1 versus FOXP2.

The p.R514H FOXP1 variant can also be compared with the previously reported p.R514C variant affecting the same residue (Table 1). At the phenotypic level, p.R514C and p.R514H FOXP1 variants lead to clinical features broadly typical of FOXP1-related disorder, although only the patient carrying the p.R514C variant displayed autistic features and behavioral problems (Sollis et al., 2016). Interestingly, Patient 2 in our study exhibited heightened sensitivity to temperature and textures, which may align with the sensory processing disorder previously reported in the proband carrying the p.R514C variant (Sollis et al., 2016). Strabismus and other visual problems were identified in all three p.R514H cases described here and in the prior p.R514C case (Table 1) (Sollis et al., 2016). To our knowledge, strabismus has been reported in two other cases of FOXP1-related disorder (Bekheir- nia et al., 2017), whereas hypermetropia (Pariani, Spencer, Graham, \& Rimoin, 2009) and hyperopic astigmatism (Bekheirnia et al., 2017) have each been reported once. It is important to note that visual problems are not a common feature of FOXP1-related disorder (Le Fevre et al., 2013), and in at least two cases, normal vision was explicitly noted (Le Fevre et al., 2013; Song, Makino, Noguchi, \& Arinami, 2015). Further studies may determine whether visual symptoms are a common and under-reported consequence of FOXP1 variants, or restricted to a subset of mutations.

We also note urogenital abnormalities including bilateral cryptorchidism, small penis, and an underdeveloped scrotum in the two male patients carrying the $\mathrm{p} . \mathrm{R} 514 \mathrm{H}$ variant. A recent study identifying eight novel heterozygous de novo FOXP1 variants found that while all patients had neurodevelopmental phenotypes consistent with FOXP1-related disorder, 6/8 also exhibited urogenital defects, including undescended testes and congenital abnormalities of the kidney and 


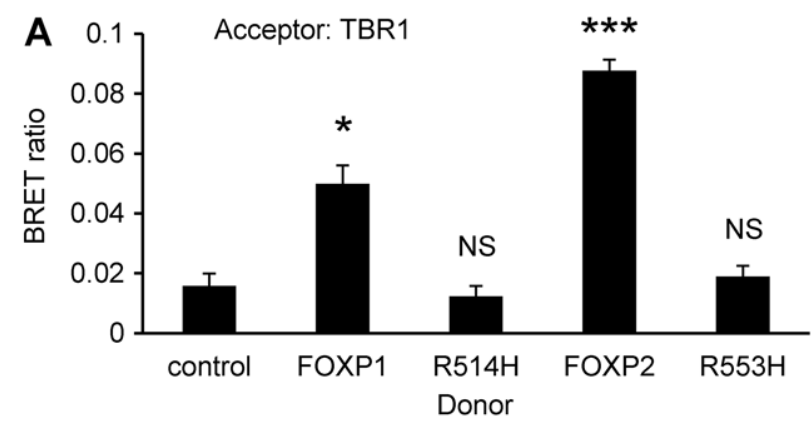

B
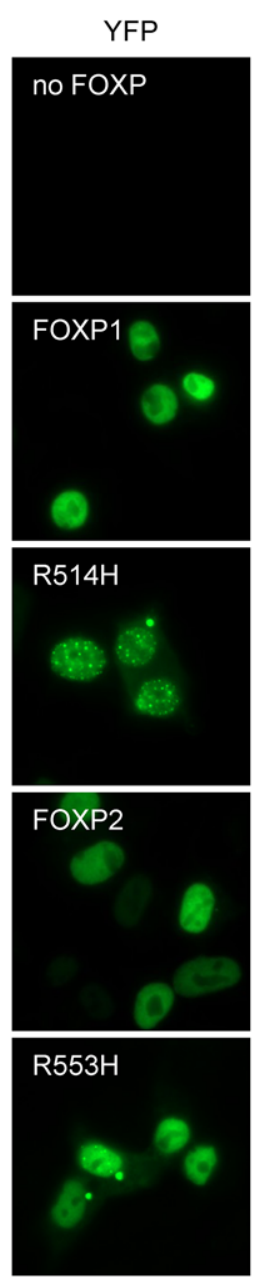
mCherryTBR1
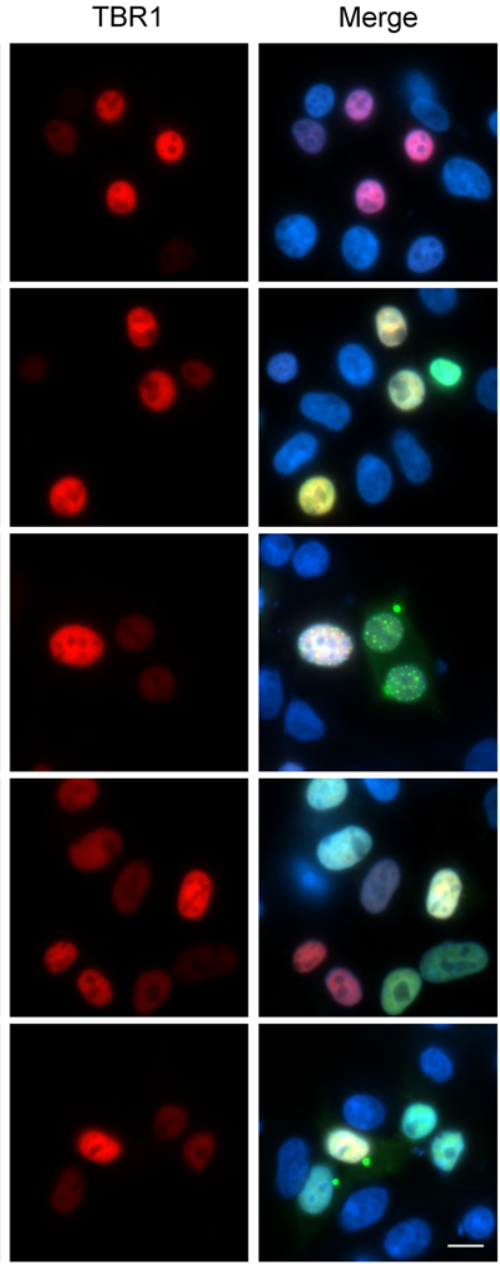

FIGURE 5 The p.R514H FOXP1 variant abolishes the interaction between FOXP1 and TBR1. A: BRET assay for interaction between the p.R514H FOXP1 variant and TBR1. The p.R553H FOXP2 variant is included for comparison. Bars represent the corrected mean BRET ratios \pm SD of one experiment performed in triplicate. Asterisks indicate significant differences compared with control ( ${ }^{*} P<0.05$, ${ }^{* * *} P<0.001$, independent two-sample $t$-test). NS, not significant. B: Fluorescence microscopy images of HEK293 cells cotransfected with TBR1 (fused to mCherry, red) and WT FOXP1, p.R514H FOXP1, WT FOXP2, or p.R553H FOXP2 (fused to YFP, green). Nuclei were stained with Hoechst 33342 (blue). Scale bar $=10 \mu \mathrm{m}$ urinary tract (CAKUT) (Bekheirnia et al., 2017). The range of mutations reported by Bekheirnia et al. (2017) includes frameshift and missense variants within the FOX domain and is consistent with variants previously reported in FOXP1-related disorder (Sollis et al., 2016). It is therefore possible that urogenital abnormalities may simply represent a variable or underdiagnosed feature of FOXP1-related disorder.

The present study has focused on the major isoform of FOXP1 to characterize the molecular effects of the $\mathrm{p} . \mathrm{R} 514 \mathrm{H}$ variant. It may be noted that seven additional isoforms have been reported, resulting from alternative splicing (Uniprot); however, their physiological relevance remains relatively unclear. All but two (isoforms 5 and 8) retain the $\mathrm{R} 514$ residue and may therefore be affected by the $\mathrm{p} . \mathrm{R} 514 \mathrm{H}$ variant. Interestingly, isoform 8 , which is specifically expressed in embryonic stem cells and displays distinct DNA-binding properties (Gabut et al., 2011), would not be disrupted by the variant, as it contains an alternative forkhead domain that does not include the mutated residue.

Eight different missense variants have now been identified at homologous sites in various FOX genes (Barış et al., 2006; Beysen et al., 2008; Brice et al., 2002; Kawase et al., 2001; Lai et al., 2001; Sen et al., 2013; Sollis et al., 2016) (Table 2; Supp. Fig. S2), and in the case of arginine 514 of FOXP1, this has occurred in at least four independent de novo events. It is therefore tempting to speculate that this site may be particularly prone to mutation. In each case, the variant is a $\mathrm{C}>\mathrm{T}$ or $\mathrm{G}>\mathrm{A}$ transition within a $\mathrm{CpG}$ dinucleotide sequence. These sequences are underrepresented in the genome, because 5methylcytosine undergoes spontaneous deamination leading to a $\mathrm{C}>\mathrm{T}$ transition (or G>A on the complementary strand). Methylated CpG sites are therefore mutational hotspots (Pfeifer, 2006), and spontaneous deamination may account for the recurrence of mutations at this position. The fact that this $\mathrm{CpG}$ sequence has been maintained in the human population is consistent with the view that a change at this site is highly deleterious, as shown in our functional assays and in the patient phenotypes.

The current study is the first, to our knowledge, to compare equivalent variants in FOXP2 and FOXP1. However, similar functional analyses have been performed to compare two homologous variants in FOXC1 (MIM\# 601090; p.R127H) and FOXC2 (MIM\# 602402; p.R121H). Both of these variants disrupted the normal nuclear localization of the protein and abolished DNA binding (Berry, Tamimi, Carle, Lehmann, \& Walter, 2005; Saleem, Banerjee-Basu, Berry, Baxevanis, \& Walter, 2003). Furthermore, while both FOXC1 and FOXC2 could act as transcriptional activators, the variants abolished or significantly reduced transcriptional activation (Berry et al., 2005; Saleem et al., 2003). The identification of very similar molecular effects for the equivalent variants in FOXP1/2 provides further evidence for a conserved role for this residue across the FOX transcription factor family.

In summary, we have identified a novel de novo missense variant in FOXP1 that is identical to the most well-studied etiological variant in FOXP2. Functional characterization revealed clear similarities between these equivalent mutations in terms of their impact on protein function. On the other hand, the phenotypic profiles of the two mutations are highly distinct, supporting divergent roles for FOXP2 and FOXP1 in neurodevelopment. 


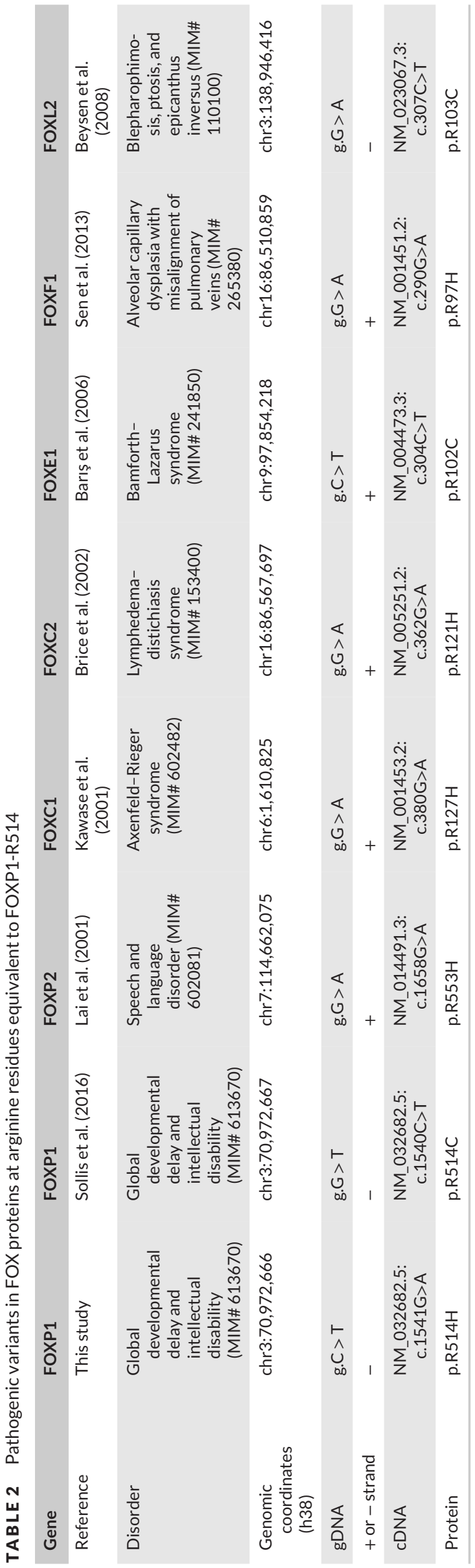

\section{ACKNOWLEDGMENTS}

We thank the patients and their families for their help in this study. This research was supported by the Max Planck Society (E.S., P.D., S.E.F.) and the Practical Research Project for Rare/Intractable Diseases from the Japan Agency for Medical Research and Development (AMED) (N.O., H.S., N.M., N.M.).

\section{REFERENCES}

Adzhubei, I. A., Schmidt, S., Peshkin, L., Ramensky, V. E., Gerasimova, A., Bork, P., ... Sunyaev, S. R. (2010). A method and server for predicting damaging missense mutations. Nature Methods, 7(4), 248-249.

Araujo, D. J., Anderson, A. G., Berto, S., Runnels, W., Harper, M., Ammanuel, S., ... Konopka, G. (2015). FoxP1 orchestration of ASD-relevant signaling pathways in the striatum. Genes \& Development, 29(20), 2081-2096.

Bacon, C., Schneider, M., Le Magueresse C, Froehlich H., Sticht, C., Gluch, C., Monyer, H., \& Rappold, G. A. (2015). Brain-specific Foxp1 deletion impairs neuronal development and causes autistic-like behaviour. Molecular Psychiatry, 20(5), 632-639.

Barış, I., Arısoy, A. E., Smith, A., Agostini, M., Mitchell, C. S., Park, S. M., ... Battaloğlu, E. (2006). A novel missense mutation in human TTF-2 (FKHL15) gene associated with congenital hypothyroidism but not athyreosis. The Journal of Clinical Endocrinology \& Metabolism, 91(10), 4183-4187.

Bekheirnia, M. R., Bekheirnia, N., Bainbridge, M. N., Gu, S., Coban Akdemir, Z. H., Gambin, T., ... Lamb, D. J. (2017). Whole-exome sequencing in the molecular diagnosis of individuals with congenital anomalies of the kidney and urinary tract and identification of a new causative gene. Genetics in Medicine, 19(4), 412-420.

Berry, F. B., Tamimi, Y., Carle, M. V., Lehmann, O. J., \& Walter, M. A. (2005). The establishment of a predictive mutational model of the forkhead domain through the analyses of FOXC2 missense mutations identified in patients with hereditary lymphedema with distichiasis. Human Molecular Genetics, 14(18), 2619-2627.

Beysen, D., De Jaegere, S., Amor, D., Bouchard, P., Christin-Maitre, S., Fellous, M., ... De Baere, E. (2008). Identification of 34 novel and 56 known FOXL2 mutations in patients with blepharophimosis syndrome. Human Mutation, 29(11), E205-E219.

Brice, G., Mansour, S., Bell, R., Collin, J. R. O., Child, A. H., Brady, A. F., ... Murday, V. A. (2002). Analysis of the phenotypic abnormalities in lymphoedema-distichiasis syndrome in 74 patients with FOXC2 mutations or linkage to 16q24. Journal of Medical Genetics, 39(7), 478-483.

Carr, C. W., Moreno-De-Luca, D., Parker, C., Zimmerman, H. H., Ledbetter, N., Martin, C. L., ... Abdul-Rahman, O. A. (2010). Chiari I malformation, delayed gross motor skills, severe speech delay, and epileptiform discharges in a child with FOXP1 haploinsufficiency. European Journal of Human Genetics, 18(11), 1216-1220.

Chabout, J., Sarkar, A., Patel, S. R., Radden, T., Dunson, D. B., Fisher, S. E., \& Jarvis, E. D. (2016). A Foxp2 mutation implicated in human speech deficits alters sequencing of ultrasonic vocalizations in adult male mice. Frontiers in Behavioral Neuroscience, 10, 197.

Cipriani, S., Nardelli, J., Verney, C., Delezoide, A. L., Guimiot, F., Gressens, P., \& Adle-Biassette, H. (2016). Dynamic expression patterns of progenitor and pyramidal neuron layer markers in the developing human hippocampus. Cerebral Cortex, 26(3), 1255-1271.

Deciphering Developmental Disorders Study. (2015). Large-scale discovery of novel genetic causes of developmental disorders. Nature, 519(7542), 223-228.

Deriziotis, P., Graham, S. A., Estruch, S. B., \& Fisher, S. E. (2014a). Investigating protein-protein interactions in live cells using bioluminescence resonance energy transfer. Journal of Visualized Experiments, (87), e51438. 
Deriziotis, P., O'Roak, B. J., Graham, S. A., Estruch, S. B., Dimitropoulou, D., Bernier, R. A., ... Fisher, S. E. (2014b). De novo TBR1 mutations in sporadic autism disrupt protein functions. Nature Communications, 5, 4954.

Estruch, S. B., Graham, S. A., Chinnappa, S. M., Deriziotis, P., \& Fisher, S. E. (2016a). Functional characterization of rare FOXP2 variants in neurodevelopmental disorder. Journal of Neurodevelopmental Disorders, 8(1), 44.

Estruch, S. B., Graham, S. A., Deriziotis, P., \& Fisher, S. E. (2016b). The language-related transcription factor FOXP2 is post-translationally modified with small ubiquitin-like modifiers. Scientific Reports, 6, 20911.

Ferland, R. J., Cherry, T. J., Preware, P. O., Morrisey, E. E., \& Walsh, C. A. (2003). Characterization of Foxp2 and Foxp1 mRNA and protein in the developing and mature brain. Journal of Comparative Neurology, 460(2), 266-279.

Feuk, L., Kalervo, A., Lipsanen-Nyman, M., Skaug, J., Nakabayashi, K., Finucane, B., ... Hannula-Jouppi, K. (2006). Absence of a paternally inherited FOXP2 gene in developmental verbal dyspraxia. The American Journal of Human Genetics, 79(5), 965-972.

Fink, A. J., Englund, C., Daza, R. A., Pham, D., Lau, C., Nivison, M., ... Hevner, R. F. (2006). Development of the deep cerebellar nuclei: Transcription factors and cell migration from the rhombic lip. Journal of Neuroscience, 26(11), 3066-3076.

French, C. A., \& Fisher, S. E. (2014). What can mice tell us about Foxp2 function? Current Opinion in Neurobiology, 28, 72-79.

French, C. A., Jin, X., Campbell, T. G., Gerfen, E., Groszer, M., Fisher, S. E., $\&$ Costa, R. M. (2012). An aetiological Foxp2 mutation causes aberrant striatal activity and alters plasticity during skill learning. Molecular Psychiatry, 17(11), 1077-1085.

Fukai, R., Hiraki, Y., Yofune, H., Tsurusaki, Y., Nakashima, M., Saitsu, H., .. Matsumoto, N. (2015). A case of autism spectrum disorder arising from a de novo missense mutation in POGZ. Journal of Human Genetics, 60(5), 277-279.

Gabut, M., Samavarchi-Tehrani, P., Wang, X., Slobodeniuc, V., O'Hanlon, D., Sung, H. K., ... Blencowe, B. J. (2011). An alternative splicing switch regulates embryonic stem cell pluripotency and reprogramming. Cell, 147(1), 132-146.

Groszer, M., Keays, D. A., Deacon, R. M. J., de Bono, J. P., Prasad-Mulcare, S., Gaub, S., ... Fisher, S. E. (2008). Impaired synaptic plasticity and motor learning in mice with a point mutation implicated in human speech deficits. Current Biology, 18(5), 354-362.

Hamdan, F. F., Daoud, H., Rochefort, D., Piton, A., Gauthier, J., Langlois, M., .. Michaud, J. L. (2010). De novo mutations in FOXP1 in cases with intellectual disability, autism, and language impairment. The American Journal of Human Genetics, 87(5), 671-678.

Hisaoka, T., Nakamura, Y., Senba, E., \& Morikawa, Y. (2010). The forkhead transcription factors, Foxp1 and Foxp2, identify different subpopulations of projection neurons in the mouse cerebral cortex. Neuroscience, 166(2), 551-563.

Kawase, C., Kawase, K., Taniguchi, T., Sugiyama, K., Yamamoto, T., Kitazawa, Y., ... Sheffield, V. C. (2001). Screening for mutations of Axenfeld-Rieger syndrome caused by FOXC1 gene in Japanese patients. Journal of Glaucoma, 10(6), 477-482.

Laffin, J. J., Raca, G., Jackson, C. A., Strand, E. A., Jakielski, K. J., \& Shriberg, L. D. (2012). Novel candidate genes and regions for childhood apraxia of speech identified by array comparative genomic hybridization. Genetics in Medicine, 14(11), 928-936.

Lai, C. S. L., Fisher, S. E., Hurst, J. A., Vargha-Khadem, F., \& Monaco, A. P. (2001). A forkhead-domain gene is mutated in a severe speech and language disorder. Nature, 413(6855), 519-523.
Le Fevre, A. K., Taylor, S., Malek, N. H., Horn, D., Carr, C. W., Abdul-Rahman, O. A., ... Hunter, M. F. (2013). FOXP1 mutations cause intellectual disability and a recognizable phenotype. American Journal of Medical Genetics Part A, 161(12), 3166-3175.

Li, H., \& Durbin, R. (2009). Fast and accurate short read alignment with Burrows-Wheeler transform. Bioinformatics, 25(14), 1754-1760.

Li, S., Weidenfeld, J., \& Morrisey, E. E. (2004). Transcriptional and DNA binding activity of the Foxp1/2/4 family is modulated by heterotypic and homotypic protein interactions. Molecular and Cellular Biology, 24(2), 809-822.

Lozano, R., Vino, A., Lozano, C., Fisher, S. E., \& Deriziotis, P. (2015). A de novo FOXP1 variant in a patient with autism, intellectual disability and severe speech and language impairment. European Journal of Human Genetics, 23(12), 1702-1707.

MacDermot, K. D., Bonora, E., Sykes, N., Coupe, A. M., Lai, C. S., Vernes, S. C., ... Fisher, S. E. (2005). Identification of FOXP2 truncation as a novel cause of developmental speech and language deficits. The American Journal of Human Genetics, 76(6), 1074-1080.

McKenna, A., Hanna, M., Banks, E., Sivachenko, A., Cibulskis, K., Kernytsky, A., ... DePristo, M. A. (2010). The Genome Analysis Toolkit: A MapReduce framework for analyzing next-generation DNA sequencing data. Genome Research, 20(9), 1297-1303.

O'Roak, B. J., Deriziotis, P., Lee, C., Vives, L., Schwartz, J. J., Girirajan, S., ... Eichler, E. E. (2011). Exome sequencing in sporadic autism spectrum disorders identifies severe de novo mutations. Nature Genetics, 43(6), 585589.

Pariani, M. J., Spencer, A., Graham, J. M. Jr, \& Rimoin, D. L. (2009). A 785 $\mathrm{kb}$ deletion of 3p14.1p13, including the FOXP1 gene, associated with speech delay, contractures, hypertonia and blepharophimosis. European Journal of Medical Genetics, 52(2-3), 123-127.

Pfeifer, G. P. (2006). Mutagenesis at methylated CpG sequences. Current Topics in Microbiology and Immunology, 301, 259-281.

Remedios, R., Huilgol, D., Saha, B., Hari, P., Bhatnagar, L., Kowalczyk, T., ... Tole, S. (2007). A stream of cells migrating from the caudal telencephalon reveals a link between the amygdala and neocortex. Nature Neuroscience, 10(9), 1141-1150.

Reuter, M. S., Riess, A., Moog, U., Briggs, T. A., Chandler, K. E., Rauch, A., ... Zweier, C. (2016). FOXP2 variants in 14 individuals with developmental speech and language disorders broaden the mutational and clinical spectrum. Journal of Medical Genetics, 54(1), 64-72.

Roll, P., Vernes, S. C., Bruneau, N., Cillario, J., Ponsole-Lenfant, M., Massacrier, A., ... Szepetowski, P. (2010). Molecular networks implicated in speech-related disorders: FOXP2 regulates the SRPX2/uPAR complex. Human Molecular Genetics, 19(24), 4848-4860.

Saleem, R. A., Banerjee-Basu, S., Berry, F. B., Baxevanis, A. D., \& Walter, M. A. (2003). Structural and functional analyses of disease-causing missense mutations in the forkhead domain of FOXC1. Human Molecular Genetics, 12(22), 2993-3005.

Sen, P., Yang, Y., Navarro, C., Silva, I., Szafranski, P., Kolodziejska, K. E., ... Stankiewicz P. (2013). Novel FOXF1 mutations in sporadic and familial cases of alveolar capillary dysplasia with misaligned pulmonary veins imply a role for its DNA binding domain. Human Mutation, 34(6), 801811.

Shu, W., Lu, M. M., Zhang, Y., Tucker, P. W., Zhou, D., \& Morrisey, E. E. (2007). Foxp2 and Foxp1 cooperatively regulate lung and esophagus development. Development, 134(10), 1991-2000.

Sin, C., Li, H., \& Crawford, D. A. (2015). Transcriptional regulation by FOXP1, FOXP2, and FOXP4 dimerization. Journal of Molecular Neuroscience, 55(2), 437-448.

Sollis, E., Graham, S. A., Vino, A., Froehlich, H., Vreeburg, M., Dimitropoulou, D., ... Fisher, S. E. (2016). Identification and functional characterization 
of de novo FOXP1 variants provides novel insights into the etiology of neurodevelopmental disorder. Human Molecular Genetics, 25(3), 546557.

Song, H., Makino, Y., Noguchi, E., \& Arinami, T. (2015). A case report of de novo missense FOXP1 mutation in a non-Caucasian patient with global developmental delay and severe speech impairment. Clinical Case Reports, 3(2), 110-113.

Srivastava, S., Cohen, J. S., Vernon, H., Barañano, K., McClellan, R., Jamal, L. ... Fatemi, A. (2014). Clinical whole exome sequencing in child neurology practice. Annals of Neurology, 76(4), 473-483.

Stroud, J. C., Wu, Y., Bates, D. L., Han, A., Nowick, K., Paabo, S., ... Chen, L. (2006). Structure of the forkhead domain of FOXP2 bound to DNA. Structure, 14(1), 159-166.

Turner, S. J., Hildebrand, M. S., Block, S., Damiano, J., Fahey, M., Reilly, S., ... Morgan, A. T. (2013). Small intragenic deletion in FOXP2 associated with childhood apraxia of speech and dysarthria. American Journal of Medical Genetics Part A, 161A(9), 2321-2326.

Vargha-Khadem, F., Watkins, K. E., Price, C. J., Ashburner, J., Alcock, K. J., Connelly, A., ... Passingham, R. E. (1998). Neural basis of an inherited speech and language disorder. Proceedings of the National Academy of Sciences of the United States of America, 95(21), 12695-12700.

Vernes, S. C., Newbury, D. F., Abrahams, B. S., Winchester, L., Nicod, J., Groszer, M., ... Fisher, S. E. (2008). A functional genetic link between distinct developmental language disorders. The New England Journal of Medicine, 359(22), 2337-2345.

Vernes, S. C., Nicod, J., Elahi, F. M., Coventry, J. A., Kenny, N., Coupe, A-M., ... Fisher, S. E. (2006). Functional genetic analysis of mutations implicated in a human speech and language disorder. Human Molecular Genetics, 15(21), 3154-3167.

Wang, B., Weidenfeld, J., Lu, M. M., Maika, S., Kuziel, W. A., Morrisey, E. E., \& Tucker, P. W. (2004). Foxp1 regulates cardiac outflow tract, endocardial cushion morphogenesis and myocyte proliferation and maturation. Development, 131(18), 4477-4487.

\section{SUPPORTING INFORMATION}

Additional Supporting Information may be found online in the supporting information tab for this article.

How to cite this article: Sollis $E$, Deriziotis $P$, Saitsu $H$, et al. Equivalent missense variant in the FOXP2 and FOXP1 transcription factors causes distinct neurodevelopmental disorders. Human Mutation. 2017;38:1542-1554. https://doi.org/ 10.1002/humu.23303 